\title{
EDITORIAL
}

\section{Message from the new Editor-in-Chief}

Hypertension Research (2013) 36, 1; doi:10.1038/hr.2012.180

$I_{c}^{t}$ $\mathrm{t}$ is a great honor for me to take on the role as the new Editor-inChief of Hypertension Research. I feel very privileged to follow in the footsteps of Professor Masatsugu Horiuchi, the previous Editorin-Chief, and his editorial team who successfully managed the journal between 2009 and 2012. During this time, they were able to significantly strengthen the position of the journal in the international arena.

Hypertension Research is the official journal of the Japanese Society of Hypertension and, through a co-partnership agreement with Nature Publishing Group, continues to increase its international profile within clinical research, increasingly welcoming contributions from all over the world. The journal publishes full papers, reviews, editorial commentaries, letters to the editor and correspondences. The main goal of the new editorial team is to establish Hypertension Research as one of the leading international journals in the field of clinical research. To achieve this, the team will endeavor to (1) publish high-quality original clinical and basic research in all fields of hypertension and the related diseases, (2) increase the readership outside Japan and (3) establish the journal as an essential resource for the international clinical research community as well as the Japanese Society of Hypertension. In addition, we have invited many international outstanding and respected scientists as Consulting editors, Associate editors and Editorial Board members to join the new editorial team. We will focus on facilitating a quick review, decision and publication process for submitted manuscripts.

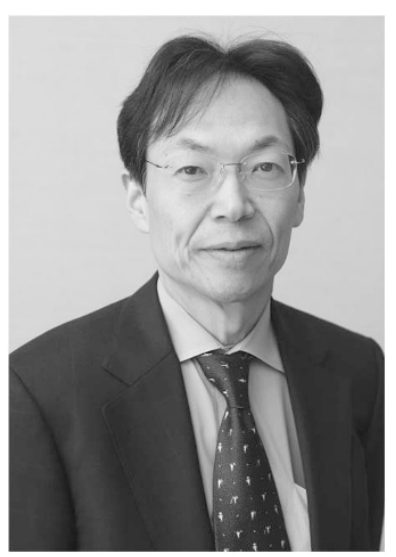

The new editorial team is looking forward to being of service to the Hypertension Research community, and welcomes the submission of your next excellent manuscript.

Shokei Kim-Mitsuyama, MD, PhD, FAHA Department of Pharmacology and Molecular Therapeutics, Kumamoto University Graduate School of Medical Sciences, Kumamoto, Japan 